\title{
Comparative effectiveness of depot and oral second generation antipsychotic drugs in schizophrenia: A nationwide study in Hungary
}

\author{
István Bitter ${ }^{a, 1}$, Lajos Katona ${ }^{\mathrm{b}, 1}$, János Zámbori ${ }^{c, 2}$, Péter Takács ${ }^{\mathrm{d}}$, \\ László Fehér ${ }^{\mathrm{d}}$, Joris Diels ${ }^{\mathrm{e}}$, Miklós Bacskai ${ }^{\mathrm{f}}$, Zsolt Lang ${ }^{\mathrm{f}}$, \\ Gergely Gyáni ${ }^{f}$, Pál Czobor ${ }^{\mathrm{a}, \mathrm{g}, *}$
}

\author{
a Department of Psychiatry and Psychotherapy, Semmelweis University, Budapest, Hungary \\ ${ }^{\mathrm{b}}$ National Health Insurance Fund Administration (NHIF), Budapest, Hungary \\ ${ }^{\mathrm{C}}$ Parexel Hungary Ltd., Budapest \\ dJanssen-Cilag Hungary Ltd., Budapest, Hungary \\ e Janssen-Cilag EMEA Ltd., Beerse, Belgium \\ ${ }^{f}$ Healthware Ltd., Budapest, Hungary \\ ${ }^{\mathrm{g}}$ Nathan S. Kline Institute for Psychiatric Research, Orangeburg, NY, USA
}

Received 22 November 2012; received in revised form 15 January 2013; accepted 7 February 2013

\author{
KEYWORDS \\ Comparative \\ effectiveness; \\ Second generation \\ antipsychotics; \\ Nationwide; \\ Full-population-based
}

\begin{abstract}
We conducted a nationwide, full-population based investigation to evaluate the comparative effectiveness of all marketed second generation antipsychotic drugs (SGA) prescribed for outpatients with the diagnosis of schizophrenia in Hungary. Using the national central register, our observational follow-up study included all patients with schizophrenia or related disorder between 01/01/2006 and $30 / 06 / 2008$. The study cohort comprised 9567 patients who started new SGA during the inclusion period (01/07/2007-30/06/2008). All-cause medication discontinuation of 8 SGAs (1 depot and 7 oral formulations) marketed during the inclusion period, and the time to all-cause discontinuation were the main outcomes. Statistical models included the Kaplan-Meier and the Cox proportional hazards models with propensity score adjustment. Patients treated with a depot formulation risperidone had the longest time to discontinuation with a median of 215 days $(95 \% \mathrm{Cl}: 181-242$ days), which was statistically significantly different compared to patients treated with the rest of the medications: olanzapine (136 days, 95\% Cl:121-153 days), aripiprazole (102 days, 95\% Cl:81-126 days), ziprasidone (93 days, $95 \% \mathrm{Cl}: 82-119$ days), quetiapine (89 days, 95\% Cl:81-100 days), clozapine (76 days, $95 \% \mathrm{Cl}: 54-92$ days), amisulpride (73 days, $95 \% \mathrm{Cl}: 62-85$ days), and risperidone ( 55 days, $95 \% \mathrm{Cl}: 41-63$ days). Our results in Hungary are partly similar to those of a recent register-based study in Finland
\end{abstract}

\footnotetext{
*Corresponding author at: Department of Psychiatry and Psychotherapy, Semmelweis University, 1083 Budapest, Balassa u. 6, Budapest, Hungary. Tel.: + 3620 8250177; fax: + 3612100336.

E-mail address: czobor.pal@med.semmelweis-univ.hu (P. Czobor).

${ }^{1}$ István Bitter MD, PhD and Lajos Katona MS are co-first authors contributed equally to the article.

${ }^{2}$ At the time of beginning of the study he worked as a psychiatry expert for NHIF.
} 
with patients who were discharged from their first hospitalization for schizophrenia (Tiihonen et al., 2006, 2011); namely the median times to all-cause medication discontinuation were $<120$ days for the majority of the oral SGA. In terms of medication differences, our data support the superior effectiveness of the depot formulation regarding all-cause discontinuation, followed by olanzapine at the efficacy rank order.

(c) 2013 Elsevier B.V. and ECNP. All rights reserved.

\section{Introduction}

Oral formulations of second generation antipsychotic drugs (SGA) have been introduced in the last two decades and recently they were followed by long-acting formulations (Kane et al., 2003; Lauriello et al., 2008). Several clinical trials addressed the effectiveness of SGA as compared to the first generation antipsychotic drugs (FGA) (Lieberman et al., 2005; Kahn et al., 2008). Additional studies focused on the effectiveness of antipsychotic drugs under real-life conditions (Kelin et al., 2011; Swartz et al., 2005). Some of these studies, especially by Medicare/Medicaid groups in the U.S. (Chen et al., 2008; Zhao et al., 2004), aimed to mimic clinical studies in order to examine the superiority of SGA over FGA and to investigate whether there is a difference in effectiveness among the various SGA.

There is a scarcity of data on the comparative effectiveness of depot antipsychotics. Leucht et al. (2011) could identify only 10 randomized studies that compared intramuscular depot with oral formulations of antipsychotic drugs in people with schizophrenia or related disorders in long-term studies defined as 1 year or longer (Leucht et al., 2011). A more recent metaanalysis including 21 randomized controlled studies (RCTs) found that oral and depot formulations of antipsychotics were similar for relapse prevention and the authors emphasized, that RCTs are less representative of real-world patients than naturalistic studies and called for further studies with "real word" patients (Kishimoto et al., 2013).

Hungary is one of the few countries where the access to health care data is guaranteed by law. Its health care system is predominantly state owned: the National Health Insurance Fund (NHIF) covers $100 \%$ of the population of 10 million inhabitants. NHIF provides de-identified patient data on healthcare services and major medical outcomes.

Through a collaboration of Academia (Department of Psychiatry and Psychotherapy, Semmelweis University), the payer (NHIF), the pharmaceutical industry (Janssen-Cilag Hungary and EMEA) and an independent consulting company (Healthware Ltd) we conducted a study to investigate the population of patients with schizophrenia in Hungary. The analyses were conducted by an independent biostatistician (LK) who worked for the government agency (the payer, NHIF). Our aim was to evaluate the comparative effectiveness of the SGA marketed in Hungary in a defined study period.

\section{Experimental procedures}

\subsection{Data, study design and patient population}

This was a parallel-group, register-based observational follow-up study of all patients in Hungary who
(1) had at least one record of schizophrenia diagnosis (F20.0-F20.9 according to the International Classification of Diseases, 10th revision ICD-10) (World Health Organization, 1992) between 01/ 01/2006 and 30/06/2008 (patient pool), and

(2) had been initiated on a new antipsychotic drug as monotherapy during the inclusion period of $01 / 07 / 2007$ and 30/06/2008 (study population).

A new antipsychotic drug was defined as no prescription of the same compound during the previous 6 months.

No further criteria were applied; the broad inclusion criteria aimed to increase the generalizability of the findings to treatment in usual-care settings using the register of the NHIF. This register allows identifying all patients in Hungary with a record of any reimbursed drug prescription since 1998. Information on patientrelated events, including therapy discontinuation, switch to a new medication, hospitalization, co-morbidity and mortality are recorded in the system both for inpatient and outpatient care.

\subsection{Study periods and treatment groups}

We studied the relative effectiveness of widely used oral and depot SGAs prescribed as monotherapy for outpatients with the schizophrenia diagnosis. In the nation-wide cohort of patients with schizophrenia in Hungary that we investigated, second generation antipsychotics constitute the majority of the total antipsychotic market (market share $=63 \%$ ). The minority share of the market (37\%) by the first generation antipsychotics (FGA) was distributed among considerably more medications than in the case of SGA, which would have made the comparison of the individual FGAs infeasible.

Monotherapy was defined as only one antipsychotic prescription at the day of therapy initiation, and no further prescription during the next 30 days (except for temporary oral supplementation at the initiation of Risperidone Long-Acting Injectable [RLAl] or dose increase). Only those SGAs were excluded from the study that were either not available during the whole inclusion period (paliperidone), or were used by only a small number of patients (sertindole and zotepine, $n<25$ ). The top part of Fig. 1 displays the study periods, whereas the bottom part (in red) shows the inclusion process and study procedures for a particular patient.

During the 1-year inclusion period, all patients were included who (a) started a new monotherapy (Day 1 in the inclusion period) between 01/07/2007 and 30/06/2008 and (b) had no other FGA or SGA prescription for the subsequent 30 days. In order to be classified as new monotherapy, no prior prescription of the same compound was allowed during the previous 6 months, which was confirmed in the retrospective period (Fig. 1). All included patients were observed for 365 days from Day 1 (observation period).

The investigation had eight parallel treatment groups focusing on the eight most frequently used SGA in the country, confirmed by sales records for the years 2008 and 2009. These medications included the following seven oral SGA: amisulpride (AMIS), aripiprazole (ARIP), clozapine (CLOZ), olanzapine (OLAN), quetiapine (QUET), risperidone (RISP), and ziprasidone (ZIPR), and one 


\section{Retrospective period}

can start at any point in the inclusion period, and goes back in time from the point of inclusion
Inclusion period

365 days to include all patients who started new SGA monotherapy during this period
Observation period

can start at any point in the inclusion period from the point of inclusion

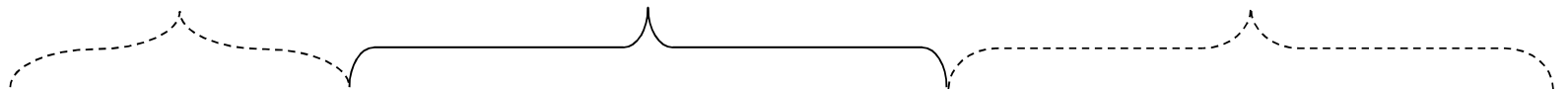

$01 / 01 / 2007$

01/07/2007

$30 / 06 / 2008$

$30 / 06 / 2009$

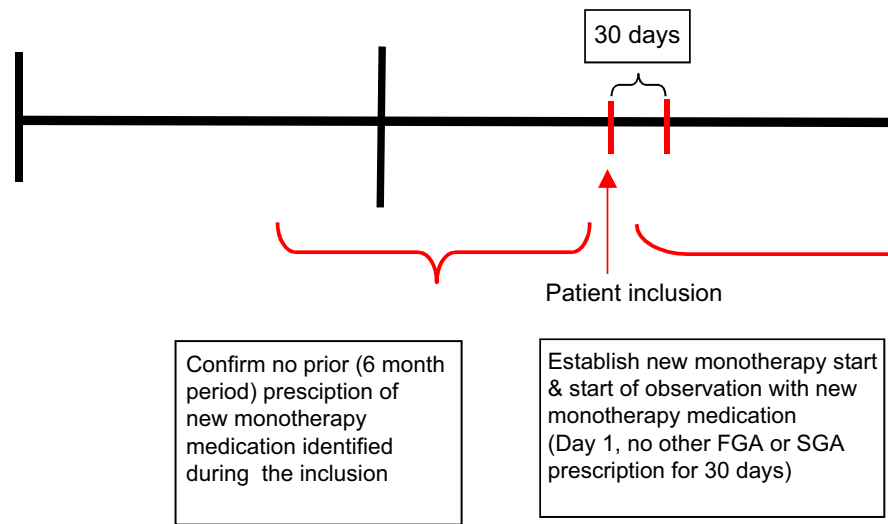

Length of observation: 365 days

Fig. 1 Study periods and procedures. (For interpretation of the references to color in this figure, the reader is referred to the web version of this article.)

parenteral depot (RLAl). Inclusion of patients into the respective treatment group was decided after confirming eligibility, as discussed above.

\subsection{Statistical analysis}

\subsubsection{Pre-processing of records of medication purchase}

The centralized NHIF register in Hungary indicates whether a patient purchased drugs with reimbursement from a pharmacy. Antipsychotic drugs for schizophrenia patients receive practically full reimbursement (patients pay a fixed fee of ca. 1 Euro/box of reimbursed medications). All outpatient disposals of antipsychotic medications are documented, filed and entered into an NHIF database. The data records contain details of the product (strength, dosage form, and formulation), and the disposal. We classified drugs according to the Anatomic Therapeutic Chemical classification system (Norwegian Institute of Public Health, 2012). Using this information, we assigned patients who took only one antipsychotic drug to a respective monotherapy treatment group; in case of RLAl, oral supplementation with risperidone was not considered a second medication. Monotherapy was defined as only one antipsychotic prescription at Day 1 (therapy initiation), with no further prescription of other FGA or SGA during the next 30 days. Except for clozapine, the median daily doses of all medications were in close agreement with the WHO DDD (amisulprid $=400 \mathrm{mg}$, aripiprazole $=15$ $\mathrm{mg}$, olanzapine $=10 \mathrm{mg}$, quetiapine $=400 \mathrm{mg}$, risperidone $=5 \mathrm{mg}$, risperidone-depot $=2.7 \mathrm{mg}$, and ziprasidone $=80 \mathrm{mg}$ ). Thus, similar to Tiihonen et al. (2011), with the exception of clozapine, we adopted the WHO DDD to calculate the duration of a prescription using drug purchasing data. For clozapine, the median dose (107 mg/day) was substantially lower than the DDD ( $300 \mathrm{mg} /$ day); thus, we adopted this value for the analyses.

\subsubsection{Outcome variables}

The primary outcome was the risk of all-cause discontinuation of the antipsychotic medication used for the assignment to a given treatment group. All-cause discontinuation during the first year after medication initiation was defined with the following events (Lieberman et al., 2005; Kahn et al., 2008): a >60 days gap in the initial monotherapy medication; switch to new medication (in conjunction with a discontinuation of the initial medication); and all-cause mortality. The 60-day threshold for gap duration was chosen because we wanted to capture the majority of patients who continue on their initial medication after pausing therapy.

The duration of gap was determined for each prescription: it was defined as the number of days elapsed with no subsequent record of prescription of the same medication from the end of the prescription duration of the initial medication. For all medications except clozapine, the duration of prescription was calculated as the total amount of the prescribed medication $(\mathrm{mg})$ divided by defined daily dose. For clozapine, the median observed daily dosage $(107 \mathrm{mg} /$ day) was used.

In case of discontinuation ( $>60$ days gap), we estimated the date of discontinuation as 14 days after the day of last prescription for the given drug. This was due to the fact that the last day of treatment in register-based cannot be defined precisely by the database. The 14-day interval after the last prescription was adopted because in case of RLAl this time period is defined by usage according to SMPC, and we wanted to apply a uniform criterion across depot and oral medications.

For the analysis of all-cause discontinuation, patients' follow-up ended when their initial treatment changed for any reason, including death, or the end of the study period, whichever occurred first. Patients without a clinical event of interest (i.e., discontinuation of initial antipsychotic, switch to another drug or death) at the end of the observation period (365 days after Day 1) were considered censored.

For all non-censored observations, time to discontinuation was defined as the time elapsed from the first prescription in the inclusion period to the date of the first of the aforementioned qualifying events (i.e., the last day of prescription duration +14 days for discontinuations; and the date of dispensation of the new medication for switches).

Secondary outcomes were hospitalization-defined as admission to active psychiatric ward-and documented suicide attempt.

\subsubsection{Analysis models}

The analyses focused on pairwise comparisons among the eight selected antipsychotic medications based on the intention-to-treat (ITT) principle. Thus, if a patient was initiated on concomitant antipsychotic medication after the index date, the initial treatment 
assignment was retained, i.e., s/he was included in the original ('assigned') treatment cohort in the analyses.

Time to all-cause medication discontinuation was analyzed by Kaplan-Meier survival analysis and the Cox proportional-hazards regression model. We report the resulting hazard ratios with $95 \%$ confidence intervals $(\mathrm{Cls})$. Pairwise analyses of individual contrasts between all included study medications constituted the main interest.

To control for potential selection bias, for the Cox regression propensity score-based adjustment was used based on the following parameters: gender, age at baseline, number and length of previous hospitalizations and medication compliance. Medication compliance was assessed on the basis of medication disposition rather than on the actual consumption. It was indexed by the prescriptionbased estimated proportion (\%) of days when an AP medication was taken as compared to total the length of the baseline period (i.e., 6 month prior to the inclusion period). These variables used for the propensity score-based adjustment were previously associated with nonadherence in the treatment of schizophrenia (Sellwood and Tarrier, 1994; Klingberg et al., 2008; Lieberman et al., 2005; Kahn et al., 2008). We estimated the conditional probability of receiving a certain drug using a multinomial log-linear model. From these probabilities, propensity scores were estimated. Results reported in this publication represent 'adjusted estimates', i.e., the propensity score and covariate based estimates of risk (hazard) ratios.

We conducted sensitivity analyses to assess the robustness of our results, including an extension of the medication gap period from 60 to 90 days. Significance level was set at $\alpha=0.05$ (two-tailed). We used the Hochberg procedure for statistical adjustment to avoid inflation of Type 1 error due to multiple comparisons.
All statistical analyses were run on the servers of NHIF and only the outputs were eligible for further investigations, without any access to patient-level data outside of NHIF. All analyses were carried out using the R-software and by the Statistical Analysis System (SAS) version 9.2 (SAS Institute, Cary, NC).

\section{Results}

\subsection{Patient eligibility and flow in the study}

As shown in Fig. 2, the patient pool consisted of 51,842 patients who received the diagnosis of schizophrenia (i.e., code F20.0-F.20.9 according to ICD-10) as either an in-, or out-patient at least once during the period of 01/01/2006$30 / 06 / 2008$. A total of 45,063 of these patients received a prescription for (any) antipsychotic drug, reimbursed by NHIF between $01 / 07 / 2007$ and 30/06/2008. Of these, 39,398 patients received SGA prescription. Among these patients, 9567 were initiated on new monotherapy with any of the eight medications, and thus constituted the study population. As shown by the respective sample sizes in Fig. 2, the most frequently prescribed initial monotherapy drug (i.e., index purchase) in the sample was risperidone, followed by olanzapine, quetiapine, RLAl, amisulpride, clozapine, aripiprazole and ziprasidone.

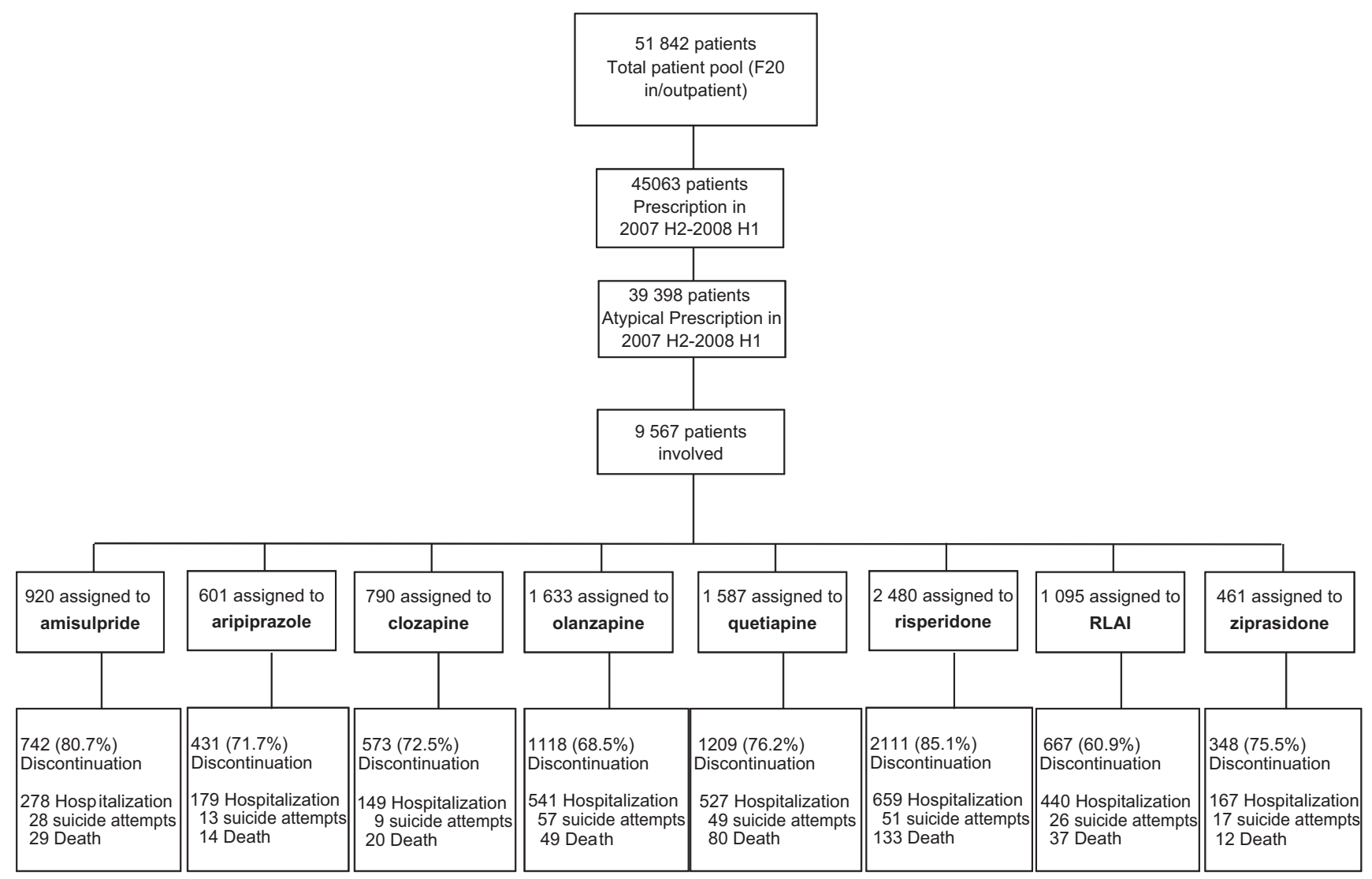

Fig. 2 Patient eligibility and flow in the study. Notes for Figure 2: All clinical events including hospitalizations, suicide attempts and deaths of any cause were determined based on the intention-to-treat principle, i.e., based on the initial treatment group membership assignment (raw number of observed events in the ITT sample). 


\subsection{Demographic and basic descriptive characteristics}

Demographic and descriptive data on the study population as a whole and broken down by treatment group are presented in Table 1.

The eight treatment groups were relatively well balanced in age ( $<8$ years difference in mean age across groups), gender ( $\leq 12 \%$ variation in gender ratio), and rate of suicide attempts ( $\leq 2 \%$ variation across groups). The groups, however, significantly differed $(p<0.05)$ in the proportion of prior hospitalizations: $58 \%$ of all patients on RLAl were hospitalized during the 6 month period preceding the inclusion in the study whereas in the other groups the hospitalization rate during the prior 6 months ranged from 23\% (clozapine) to $44 \%$ (olanzapine).

\subsection{Patient disposition}

The percentage of patients who discontinued the initial therapy is depicted in the last row of Fig. 2. Only a small proportion of patients completed the study period without discontinuing the originally assigned (index) medication. The lowest proportion of discontinuation was in the RLAl group $(60.9 \%)$, followed by olanzapine $(68.5 \%)$, aripiprazole (71.7\%) clozapine (72.5\%), ziprasidone (75.5\%), quetiapine (76.2\%), amisulpride (80.7\%) and oral risperidone $(85.1 \%)$. Further details on patient disposition are provided in the Web Extra Material.

\subsection{Relative effectiveness: all-cause discontinuation of initial (index) treatment}

Fig. 3 shows the results of the non-parametric Kaplan-Meier survival analysis of time to discontinuation for any reason, excluding deaths, of the eight antipsychotics in the first year after medication initiation.

The left panel of Fig. 3 shows time to discontinuation KM curves for each of the eight antipsychotic treatments while the right panel depicts the point estimates and $95 \%$ confidence intervals $(\mathrm{Cl})$ of median time to discontinuation based on the eight KM curves.

Compared with patients on oral antipsychotics, RLAl treated patients had a longer time to discontinuation with a median

Table 1 Demographic and basic descriptive data of the study population.

\begin{tabular}{llllll}
\hline $\begin{array}{l}\text { Treatment } \\
\text { group }\end{array}$ & $\begin{array}{l}N \\
\text { (total /group) }\end{array}$ & $\begin{array}{l}\text { Mean } \\
\text { age (year) }\end{array}$ & \multicolumn{1}{l}{$\begin{array}{l}\text { Women, } \\
N(\%)\end{array}$} & $\begin{array}{l}\text { Hospitalizations }{ }^{\mathrm{a}}, 6 \\
\text { months prior baseline N (\%) }\end{array}$ & $\begin{array}{l}\text { Suicide attempts }{ }^{\mathrm{b}}, 6 \\
\text { months prior baseline } N(\%)\end{array}$ \\
\hline Amisulpride & 920 & 47.01 & $569(62 \%)$ & $330(36 \%)$ & $26(3 \%)$ \\
Aripiprazole & 601 & 43.26 & $375(62 \%)$ & $221(37 \%)$ & $13(2 \%)$ \\
Clozapine & 790 & 48.31 & $420(53 \%)$ & $184(23 \%)$ & $9(1 \%)$ \\
Olanzapine & 1633 & 46.27 & $958(59 \%)$ & $715(44 \%)$ & $45(3 \%)$ \\
Quetiapine & 1587 & 49.72 & $1038(65 \%)$ & $631(40 \%)$ & $34(2 \%)$ \\
Risperidone & 2480 & 50.63 & $1484(60 \%)$ & $826(33 \%)$ & $40(2 \%)$ \\
RLAl & 1095 & 45.62 & $618(56 \%)$ & $640(58 \%)$ & $28(3 \%)$ \\
Ziprasidone & 461 & 45.65 & $300(65 \%)$ & $156(34 \%)$ & $11(2 \%)$
\end{tabular}

${ }^{a}$ Number of patients hospitalized in psychiatric ward in the 6 month period prior baseline.

${ }^{\mathrm{b}}$ Number of patients with suicide attempts in the 6 month period prior baseline.
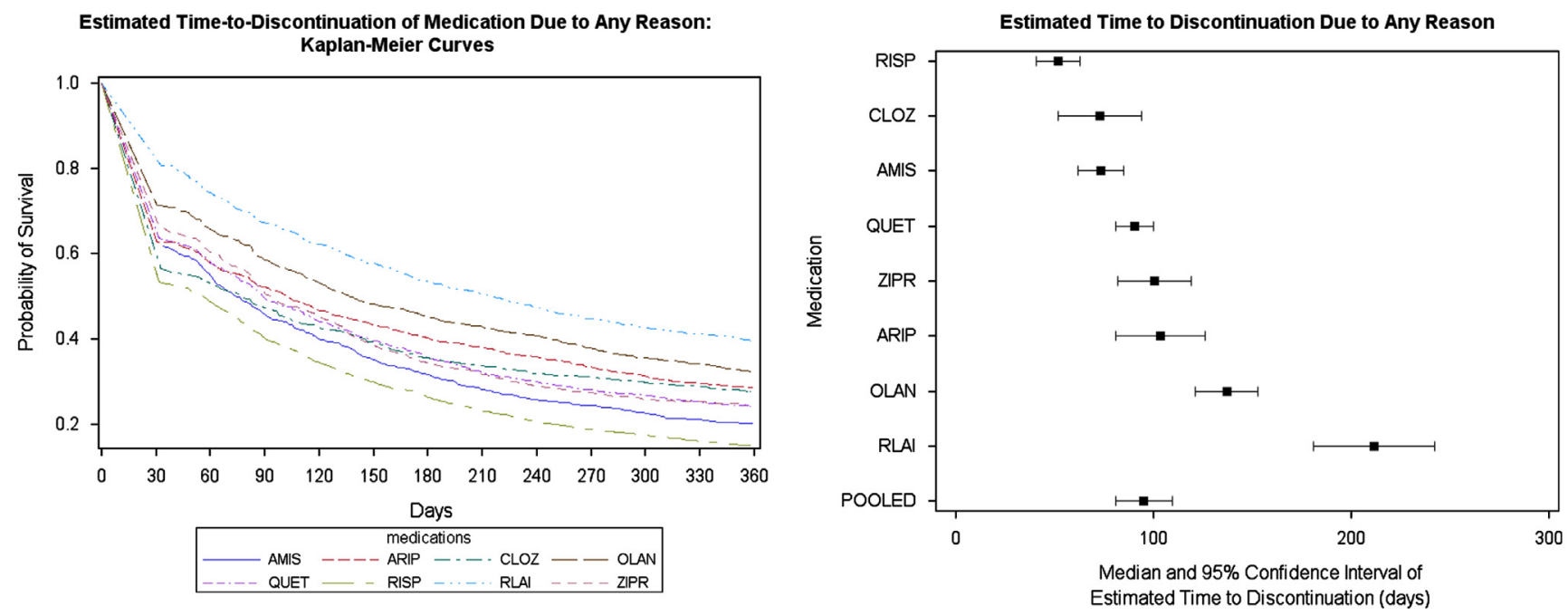

Fig. 3 Kaplan-Meier estimates for time-to-discontinuation for any reason, based on raw data. 
value of 215 days (95\%Cl:181-242 days), which was statistically significantly different compared to patients treated with the rest of the medications: olanzapine (136 days, $95 \% \mathrm{Cl}: 121-153$ days), aripiprazole (102 days, 95\% Cl:81-126 days), ziprasidone (93 days, $95 \% \mathrm{Cl}: 82-119$ days), quetiapine (89 days, $95 \% \mathrm{Cl}: 81-$ 100 days), clozapine (76 days, $95 \% \mathrm{Cl}: 54-92$ days), amisulpride (73 days, $95 \% \mathrm{Cl}: 62-85$ days), and risperidone (55 days, $95 \% \mathrm{Cl}$ : 41-63 days).

Table 2 shows the adjusted hazard ratios for all-cause treatment discontinuation of the eight antipsychotic treatments. Treatment with RLAl was associated with significantly lower risk of all-cause discontinuation than treatment with the other medications, whereas olanzapine was also superior to the remaining six medications. Four of the oral medications (ARIP, CLOZ, QUET, ZIPR) did not significantly differ from each other in terms of all-cause discontinuations. Additionally, the hazard rate for discontinuation was significantly lower for aripiprazole as compared to amisulpride, and for aripiprazole, quetiapine and ziprasidone as compared to risperidone.

For the primary analyses, discontinuation was defined by the first medication gap with $>60$ days after medication initiation (see Section 2). To examine whether this choice had impacted the group comparison results, we conducted sensitivity analyses extending the gap period to 90 days. The relative effectiveness of medications remained generally similar with the adoption of the alternative criterion for the gap.

We also investigated the proportion of patients who received polypharmacy, defined as at least one prescription of another SGA before medication discontinuation. We found that the proportion of patients across the majority of study groups was around $25 \%$, and varied within relatively narrow $( \pm 10 \%)$ range for all treatments.

Table 2 Adjusted hazard ratios of all-cause discontinuations by treatment: pairwise comparisons among individual treatments, adjusted for differences in baseline characteristics of the patients (propensity score included in the Cox regression).

\begin{tabular}{|c|c|c|c|c|c|c|c|c|}
\hline $\begin{array}{l}\text { Adjusted hazard } \\
\text { ratio }(95 \% \mathrm{CL}) p \text { - } \\
\text { value }\end{array}$ & $\begin{array}{l}\text { AMIS } \\
(n=920)\end{array}$ & $\begin{array}{l}\text { ARIP } \\
(n=601)\end{array}$ & $\begin{array}{l}\text { CLOZ } \\
(n=790)\end{array}$ & $\begin{array}{l}\text { OLAN } \\
(n=1633)\end{array}$ & $\begin{array}{l}\text { QUET } \\
(n=1587)\end{array}$ & $\begin{array}{l}\text { RISP } \\
(n=2480)\end{array}$ & $\begin{array}{l}\text { RLAl } \\
(n=1095)\end{array}$ & $\begin{array}{l}\text { ZIPR } \\
(n=461)\end{array}$ \\
\hline $\begin{array}{l}\text { AMIS } \\
(n=920)\end{array}$ & - & $\begin{array}{l}1.18 \\
(1.04-1.34) \\
p=0.117\end{array}$ & $\begin{array}{l}1.07 \\
(0.93-1.24) \\
p=0.92\end{array}$ & $\begin{array}{l}1.38^{*} \\
(1.25-1.53) \\
p=0.0019\end{array}$ & $\begin{array}{l}1.11 \\
(1.01-1.22) \\
p=0.37\end{array}$ & $\begin{array}{l}0.94 \\
(0.85-1.04) \\
p=0.92\end{array}$ & $\begin{array}{l}1.68^{*} \\
(1.48-1.90) \\
p=0.0019\end{array}$ & $\begin{array}{l}1.04 \\
(0.91-1.20) \\
p=0.92\end{array}$ \\
\hline $\begin{array}{l}\text { ARIP } \\
(n=601)\end{array}$ & $\begin{array}{l}0.85 \\
(0.75-0.98) \\
p=0.117\end{array}$ & - & $\begin{array}{l}0.99 \\
(0.84-1.17) \\
p=0.92\end{array}$ & $\begin{array}{l}1.19 * \\
(1.06-1.34) \\
p=0.045\end{array}$ & $\begin{array}{l}0.93 \\
(0.83-1.04) \\
p=0.92\end{array}$ & $\begin{array}{l}0.79 * \\
(0.70-0.89) \\
p=0.0036\end{array}$ & $\begin{array}{l}1.40^{*} \\
(1.21-1.62) \\
p=0.0019\end{array}$ & $\begin{array}{l}0.89 \\
(0.77-1.03) \\
p=0.92\end{array}$ \\
\hline $\begin{array}{l}\text { CLOZ } \\
(n=790)\end{array}$ & $\begin{array}{l}0.93 \\
(0.80-1.08) \\
p=0.92\end{array}$ & $\begin{array}{l}1.01 \\
(0.86-1.18) \\
p=0.92\end{array}$ & - & $\begin{array}{l}1.17 \\
(1.02-1.33) \\
p=0.22\end{array}$ & $\begin{array}{l}1.02 \\
(0.89-1.16) \\
p=0.92\end{array}$ & $\begin{array}{l}0.84 \\
(0.74-0.96) \\
p=0.12\end{array}$ & $\begin{array}{l}1.37^{*} \\
(1.17-1.60) \\
p=0.0019\end{array}$ & $\begin{array}{l}0.93 \\
(0.77-1.11) \\
p=0.92\end{array}$ \\
\hline $\begin{array}{l}\text { OLAN } \\
(n=1633)\end{array}$ & $\begin{array}{l}0.72^{*} \\
(0.65-0.80) \\
p=0.0019\end{array}$ & $\begin{array}{l}0.84^{*} \\
(0.75-0.94) \\
p=0.045\end{array}$ & $\begin{array}{l}0.86 \\
(0.75-0.98) \\
p=0.22\end{array}$ & - & $\begin{array}{l}0.78^{*} \\
(0.72-0.85) \\
p=0.0019\end{array}$ & $\begin{array}{l}0.65^{*} \\
(0.59-0.70) \\
p=0.0019\end{array}$ & $\begin{array}{l}1.16^{*} \\
(1.04-1.30) \\
p=0.0096\end{array}$ & $\begin{array}{l}0.74^{*} \\
(0.65-0.84) \\
p=0.0019\end{array}$ \\
\hline $\begin{array}{l}\text { QUET } \\
(n=1587)\end{array}$ & $\begin{array}{l}0.90 \\
(0.82-0.99) \\
p=0.37\end{array}$ & $\begin{array}{l}1.08 \\
(0.96-1.21) \\
p=0.92\end{array}$ & $\begin{array}{l}0.98 \\
(0.86-1.12) \\
p=0.92\end{array}$ & $\begin{array}{l}1.29^{*} \\
(1.18-1.40) \\
p=0.0019\end{array}$ & - & $\begin{array}{l}0.86^{*} \\
(0.79-0.93) \\
p=0.0051\end{array}$ & $\begin{array}{l}1.58^{*} \\
(1.41-1.77) \\
p=0.0019\end{array}$ & $\begin{array}{l}0.96 \\
(0.85-1.09) \\
p=0.92\end{array}$ \\
\hline $\begin{array}{l}\text { RISP } \\
(n=2480)\end{array}$ & $\begin{array}{l}1.06 \\
(0.96-1.18) \\
p=0.92\end{array}$ & $\begin{array}{l}1.26^{*} \\
(1.12-1.43) \\
p=0.0036\end{array}$ & $\begin{array}{l}1.19 \\
(1.04-1.36) \\
p=0.12\end{array}$ & $\begin{array}{l}1.55^{*} \\
(1.42-1.68) \\
p=0.0019\end{array}$ & $\begin{array}{l}1.16^{*} \\
(1.07-1.26) \\
p=0.0051\end{array}$ & - & $\begin{array}{l}1.88^{*} \\
(1.67-2.10) \\
p=0.0019\end{array}$ & $\begin{array}{l}1.20 \\
(1.05-1.37) \\
p=0.084\end{array}$ \\
\hline $\begin{array}{l}\text { RLAl } \\
(n=1095)\end{array}$ & $\begin{array}{l}0.60^{*} \\
(0.53-0.67) \\
p=0.0019\end{array}$ & $\begin{array}{l}0.71 * \\
(0.62-0.82) \\
p=0.0019\end{array}$ & $\begin{array}{l}0.73^{*} \\
(0.63-0.85) \\
p=0.0019\end{array}$ & $\begin{array}{l}0.86^{*} \\
(0.77-0.96) \\
p=0.0096\end{array}$ & $\begin{array}{l}0.63^{*} \\
(0.57-0.71) \\
p=0.0019\end{array}$ & $\begin{array}{l}0.53^{*} \\
(0.48-0.60) \\
p=0.0019\end{array}$ & - & $\begin{array}{l}0.63^{*} \\
(0.54-0.75) \\
p=0.0019\end{array}$ \\
\hline $\begin{array}{l}\text { ZIPR } \\
(n=461)\end{array}$ & $\begin{array}{l}0.96 \\
(0.84-1.10) \\
p=0.92\end{array}$ & $\begin{array}{l}1.13 \\
(0.98-1.31) \\
p=0.92\end{array}$ & $\begin{array}{l}1.08 \\
(0.90-1.30) \\
p=0.92\end{array}$ & $\begin{array}{l}1.35^{*} \\
(1.18-1.53) \\
p=0.0019\end{array}$ & $\begin{array}{l}1.04 \\
(0.92-1.18) \\
p=0.92\end{array}$ & $\begin{array}{l}0.83 \\
(0.73-0.95) \\
p=0.084\end{array}$ & $\begin{array}{l}1.58^{*} \\
(1.34-1.86) \\
p=0.0019\end{array}$ & - \\
\hline
\end{tabular}

Cell layout:

- Adjusted hazard ratio (HR), i.e., risk of event in the group depicted in row as compared to group depicted in column

- (i.e., a value of $<1$ indicates a risk reduction for group in row).

- Upper and Lower $95 \%$ confidence limits of HR.

- adjusted $p$-value in pairwise comparisons after correction for multiple testing based on the Hocherg procedure. 


\section{Discussion}

Physicians may consider a number of variables before choosing an antipsychotic for their patient with the diagnosis of schizophrenia, e.g. the efficacy, tolerability, safety and price of the drugs, and patient preference. Efficacy of antipsychotics for obtaining marketing authorization by regulatory agencies has to be tested against placebo which does not provide the clinician with guidance for selecting the "right drug for the right patient". Direct comparisons between antipsychotics, especially between more than two antipsychotics are scarce or not existing.

Large observational studies are helpful; however, they also have limitations regarding generalizability, due to the unbalanced number of patients with different antipsychotics and large regional variability in the risk of treatment discontinuation (e.g. Bitter et al., 2008) or the limited, number of antipsychotics in the study (e.g. Thomas et al., 2010). In general, the observational (non-randomized) design limits internal validity, and thereby endangers external validity.

Analyses of prescription databases, which contain data from real-world practice settings with a large sample size, may be biased since they focused on specific populations (e.g., Medicaid or Medicare patients in the U.S.; Chen et al. (2008)). Moreover, when several forms of coverage are available individual prescription databases can be incomplete since patients may receive care from multiple sources; furthermore, the results can be confounded since patients may not maintain continuous eligibility within one system.

Nationwide register-based studies may overcome some of the pitfalls of registration and observational studies and of the analyses of insurance databases. The nationwide register-based study conducted in Finland by Tiihonen et al. (2006) used an observational follow-up design and investigated discontinuation due to any cause as a principal measure of effectiveness. The Finnish study focused on the relative effectiveness of first and second generation antipsychotics in a nationwide patient cohort in community care after first hospitalization due to schizophrenia or schizoaffective disorder. Additionally, in a further analysis of the Finnish nationwide register data Tiihonen et al. (2011) compared oral and depot neuroleptics in terms of all-cause discontinuation and rehospitalization after discharge from first hospitalization.

Our study is similar to Tiihonen et al. $(2006,2011)$ study in that it used an observational follow-up design with all-cause treatment discontinuation as the principal effectiveness measure. However, unlike the Finnish study, our study included all patients with the diagnosis of schizophrenia and other psychotic disorders in Hungary who had been prescribed a new SGA during the inclusion period. The observational follow-up design with the availability of nationwide register database provided a unique opportunity to investigate the relative effectiveness of SGAs. We were able to study data from a real-world setting, using a single database with no limitation regarding the population selection, and with a large sample size that allowed for a head-to-head comparison of many of the currently marketed SGA.

One of the major conclusions from the Finnish studies was that "only a minority of patients adhere to their initial antipsychotic during the first 60 days after discharge from their first hospitalization for schizophrenia" (Tiihonen et al., 2011). Our findings based on the full-population of schizophrenia patients in Hungary indicated somewhat longer times to all-cause discontinuation, but still the median survival times were less than 120 days for the majority of oral APs.

Overall, our data regarding medication differences are similar to the Finnish data (Tiihonen et al., 2006, 2011), supporting the superior efficacy of a depot formulation and the efficacy rank order of oral olanzapine and risperidone. The significant differences in the time to discontinuation between the patients treated with oral SGAs or RLAI in this naturalistic study supports the conclusions of a metaanalysis that recent challenges of the benefits of depot formulations over oral formulations of antipsychotics may be related to the fact, that RCTs are less representative of real-world patients than naturalistic studies (Kishimoto et al., 2013). The fact that clozapine did not perform as well in our as in the Finnish study might be linked to the use of clozapine after first hospitalization in Finland, while in the entire, more chronic population (mainly in treatment resistant patients as defined by the summary of the product characteristics of clozapine) in Hungary.

The present study has limitations. First, the fact that the last day of treatment cannot be determined precisely by the register-based database may have introduced an additional variability into our estimates of time to all-cause discontinuation. The fact that we adopted a uniform criterion for medication discontinuation (14 days after the last dispensation) across all oral and depot medications makes it unlikely that the results of our comparisons were confounded by this problem. Second, approximately one quarter of the patients received polypharmacy with another SGA before medication discontinuation. However, the proportions of polypharmacy were somewhat lower than those reported in the Intercontinental Schizophrenia Outpatient Health Outcomes (IC$\mathrm{SOHO}$ ) investigation, an observational study (Dossenbach et al., 2005), and exhibited only a small variation across treatments. This makes it unlikely that the use of polypharmacy introduced a bias into our medication comparisons. Finally, our study was observational with no ratings of psychopathology or measures of side effects/tolerability; and with no random treatment allocation, which may have introduced selection bias, thereby limiting the external validity of the results. While we applied propensity scorebased adjustment to counter this problem, future studies may wish to address this issue further.

\section{Role of funding source}

Funding: Janssen-Cilag Hungary Ltd, Budapest, Hungary.

Sponsor employees had participated in the study design, data interpretation, and writing of the report. The sponsor of the study did not participate in the data collection and data analysis. Employees of an independent consulting company (Healthware Ltd) received funding for contribution to the study design and data analyses. A lead-author (LK) and independent biostatistician had full access to all the patient-level data from the centralized national insurance database used for the study. The corresponding author had full access to all the aggregate data used for the study, and had final responsibility for the decision to submit for publication. 


\section{Contributors}

$\mathrm{IB}$ and $\mathrm{LK}$ are co-first authors contributed equally to the article.

PT, LF, PC, LK, JD, IB, JZ, and MB designed the study. PT and LF obtained funding from Janssen. $L K, M B, P C$ and $Z L$ analyzed the data. PC, IB, PT, LF, LK, MB, JD, GG, and JZ interpreted the results, and IB, PT, LK and PC drafted the report. PC, GG, and PT prepared the tables and figures. All authors participated in the critical revision of the manuscript. All authors approved the final version.

\section{Conflict of interest}

JD, LF, TP are employees of JANSSEN.

LK, JZ, and PC report no conflict of interest, JZ works for Parexel company.

$M B$, ZL, and GG are consulting company (Healthware Ltd) employees.

IB has been an advisory board member/consultant/lecturer for or received research support from Astra-Zeneca, Bristol-Myers Squibb, Eli Lilly, EGIS, Janssen, Lundbeck, Novartis, Pfizer, Richter and Schering-Plough.

\section{Acknowlegments}

None.

\section{References}

Bitter, I., Treuer, T., Dyachkova, Y., Martenyi, F., McBride, M., Ungvari, G.S., 2008. Antipsychotic prescription patterns in outpatient settings: 24-month results from the Intercontinental Schizophrenia Outpatient Health Outcomes (IC-SOHO) study. Eur Neuropsychopharmacol 18, 170-180.

Chen, L., McCombs, J.S., Park, J., 2008. Duration of antipsychotic drug therapy in real-world practice: a comparison with CATIE trial results. Value Health 11, 487-496.

Dossenbach, M., Arango-Davila, C., Silva, I.H., Landa, E., Aguilar, J., Caro, O., Leadbetter, J., Assuncao, S., 2005. Response and relapse in patients with schizophrenia treated with olanzapine, risperidone, quetiapine, or haloperidol: 12-month follow-up of the Intercontinental Schizophrenia Outpatient Health Outcomes (IC-SOHO) study. J. Clin. Psychiatry. 66, 1021-1030.

Kahn, R.S., Fleischhacker, W.W., Boter, H., Davidson, M., Vergouwe, Y., Keet, I.P., Gheorghe, M.D., Rybakowski, J.K., Galderisi, S., Libiger, J., Hummer, M., Dollfus, S., Lopez-lbor, J.J., Hranov, L.G., Gaebel, W., Peuskens, J., Lindefors, N., Riecher-Rossler, A., Grobbee, D.E., 2008. Effectiveness of antipsychotic drugs in first-episode schizophrenia and schizophreniform disorder: an open randomised clinical trial. Lancet 371, 1085-1097.

Kane, J.M., Eerdekens, M., Lindenmayer, J.P., Keith, S.J., Lesem, M., Karcher, K., 2003. Long-acting injectable risperidone: efficacy and safety of the first long-acting atypical antipsychotic. Am. J. Psychiatry 160, 1125-1132.

Kelin, K., Lambert Jr., T., Brnabic, A.J., Newton, R., Ye, W., Escamilla, R.I., Chen, K.P., Don, L., Montgomery, W., Karagianis, J., Ascher-Svanum, H., 2011. Treatment discontinuation and clinical outcomes in the 1-year naturalistic treatment of patients with schizophrenia at risk of treatment nonadherence. Patient Prefer. Adherence 5, 213-222.
Kishimoto, T., Robenzadeh, A., Leucht, C., Leucht, S., Watanabe, K., Mimura, M., Borenstein, M., Kane, J.M., Correll, C.U.. Longacting injectable vs oral antipsychotics for relapse prevention in schizophrenia: a meta-analysis of randomized trials. Schizophr Bull., in press (online: 2012 Dec 17), PMID:23256986.

Klingberg, S., Schneider, S., Wittorf, A., Buchkremer, G., Wiedemann, G., 2008. Collaboration in outpatient antipsychotic drug treatment: analysis of potentially influencing factors. Psychiatry Res. 161, 225-234.

Lauriello, J., Lambert, T., Andersen, S., Lin, D., Taylor, C.C., McDonnell, D., 2008. An 8-week, double-blind, randomized, placebo-controlled study of olanzapine long-acting injection in acutely ill patients with schizophrenia. J. Clin. Psychiatry 69, 790-799.

Leucht, C., Heres, S., Kane, J.M., Kissling, W., Davis, J.M., Leucht, S., 2011. Oral versus depot antipsychotic drugs for schizophrenia-a critical systematic review and meta-analysis of randomised long-term trials. Schizophr. Res. 127, 83-92.

Lieberman, J.A., Stroup, T.S., McEvoy, J.P., Swartz, M.S., Rosenheck, R.A., Perkins, D.O., Keefe, R.S., Davis, S.M., Davis, C.E., Lebowitz, B.D., Severe, J., Hsiao, J.K., 2005. Effectiveness of antipsychotic drugs in patients with chronic schizophrenia. N. Engl. J. Med. 353, 1209-1223.

Norwegian Institute of Public Health, 2012. ATC/DDD Index. <http://www.whocc.no/atc_ddd_index/ > (accessed 23.05.12).

Sellwood, W., Tarrier, N., 1994. Demographic factors associated with extreme non-compliance in schizophrenia. Soc. Psychiatry Psychiatr. Epidemiol. 29, 172-177.

Swartz, M., Zhu, B., Ascher-Svanum, H., et al., 2005 Time to all-cause discontinuation of atypical versus typical antipsychotics in the naturalistic treatment of schizophrenia. In: Proceedings of the Poster Presented at the International Congress on Schizophrenia Research, Conference Abstract. April 2005, Savannah, GA.

World Health Organization: The ICD-10 Classification of Mental and Behavioural Disorders, 1992. Clinical Descriptions and Diagnostic Guidelines. World Health Organization, Geneva.

Thomas, S.H., Drici, M.D., Hall, G.C., Crocq, M.A., Everitt, B., Lader, M.H., Le, J.C., Naber, D., Priori, S., Sturkenboom, M., Thibaut, F., Peuskens, J., Mittoux, A., Tanghoj, P., Toumi, M., Moore, N.D., Mann, R.D., 2010. Safety of sertindole versus risperidone in schizophrenia: principal results of the sertindole cohort prospective study (SCoP). Acta Psychiatr. Scand. 122, 345-355.

Tiihonen, J., Haukka, J., Taylor, M., Haddad, P.M., Patel, M.X., Korhonen, P., 2011. A nationwide cohort study of oral and depot antipsychotics after first hospitalization for schizophrenia. Am. J. Psychiatry 168, 603-609.

Tiihonen, J., Wahlbeck, K., Lonnqvist, J., Klaukka, T., loannidis, J.P., Volavka, J., Haukka, J., 2006. Effectiveness of antipsychotic treatments in a nationwide cohort of patients in community care after first hospitalisation due to schizophrenia and schizoaffective disorder: observational follow-up study. Br. Med. J. 333, 224.

Zhao, Z., Damler, R.M., Jackson, E.A., Ramsey, J., 2004. Atypical antipsychotic treatment adherence and persistence in a state Medicaid program. In: Proceedings of the Poster Presented at the Annual Meetings of the International Society for Pharmacoeconomics and Outcomes Research, Conference Abstract. May 2004, Arlington, VA. 